\title{
The Stock Return Comovements: A Study of the European and the Japanese Equity Markets
}

\author{
Chikashi Tsuji ${ }^{1}$ \\ ${ }^{1}$ Department of Social Systems and Management, Graduate School of Systems and Information Engineering, \\ University of Tsukuba, Ibaraki, Japan \\ Correspondence: Chikashi Tsuji, Department of Social Systems and Management, Graduate School of Systems \\ and Information Engineering, University of Tsukuba, 1-1-1 Tennodai, Tsukuba, Ibaraki 305-8573, Japan. Tel: \\ 81-29-853-2111. E-mail: mail_sec_low@minos.ocn.ne.jp
}

Received: March 28, 2012

Accepted: April 9, $2012 \quad$ Online Published: July 1, 2012

doi:10.5539/ibr.v5n8p1

URL: http://dx.doi.org/10.5539/ibr.v5n8p1

The research is financed by the Japan Society for the Promotion of Science and the author greatly acknowledges their generous financial assistance for this research.

\begin{abstract}
In this paper, the time-series developments of covariations of returns between the Japanese stock markets and the European stock markets are empirically examined. We analyze these comovements by dividing sample periods into several terms that are before and after the Lehman Shock in the US. In this study, it is firstly clarified that the linkage of stock returns of the Japanese markets and the European markets recently gradually increased. Moreover, it is secondly identified that in the period right after the US Lehman Shock, the covariations between stock returns in Japan and in several European countries highly increased.
\end{abstract}

Keywords: international stock market integration, European stock markets, Japanese stock markets, stock return comovements

\section{Introduction}

Academic researchers and practitioners are more and more paying attention to the time-series comovements of international stock returns. This is one of the important research topics in business, finance, and economics. There are already several exciting and seminal papers with regard to the international stock return covariations. These studies are, for example, the papers by Heston and Rouwenhorst (1994), Bekaert and Harvey (1995), Rouwenhorst (1999), Longin and Solnik (2001), Bekaert et al. (2002), Forbes and Rigobon (2002), Bekaert et al. (2005), Pukthuanthong and Roll (2009), Boyson et al. (2010), and Billio et al. (2012).

On the other hand, as far as we know, there seem to be few academic papers that scrutinize the stock return relationships by focusing on the connections between the Japanese stock markets and the European markets. Moreover, we consider that, there may be little research which examines the above linkage by dividing the analyzing periods into several time-periods before and after the US Lehman Shock. With these backgrounds and motivations, in this paper, we attempt to analyze and discuss the developments of stock return time-series covariations between the Japanese equity markets and the European stock markets. This is our primary concern in this paper. In order to scrutinize these relationships, we exploit the stock indices data from the Morgan Stanley Capital International for twelve European stock markets. In addition to these data, we use the data of the Japanese stock market index, the Tokyo Stock Price Index.

Our empirical researches in this paper supply the following contributions. First, we statistically found that recently, the time-series covariations of stock returns between the Japanese markets and the European markets gradually increased. Secondly, this paper also empirically derived the evidence that in the sub-period right after the US Lehman Shock, the time-series comovements between returns in these equity markets of two regions generally increased.

Documenting the organization of this paper, the rest of the paper is as follows. Firstly, Section 2 describes the data, secondly, Section 3 explains our research design, and Section 4 documents our empirical results. After that, Section 5 describes the interpretation and implications from our empirical results, and finally, Section 6 concludes the paper. 


\section{Data}

Explaining the data, we exploit the weekly stock returns computed from the Morgan Stanley Capital International Indices and weekly stock returns derived from the Tokyo Stock Price Index. All indices are local currency basis, and all data are supplied through the Nikkei Inc. In this paper, we statistically test the stock return correlation coefficients between the Japanese and the European stock markets. More specifically, the focus of our analysis is on twelve stock markets of Austria, Belgium, France, Germany, Greece, Ireland, Italy, Netherlands, Portugal, Spain, Switzerland, and England.

\section{Research Design}

In this section, our research design is explained. Our full weekly sample period is from 24 November 2001 through 11 February 2012. In order to conduct our empirical analysis, we first divide the full sample periods into the following four sub-periods. More concretely, they are two sub-periods of 178 week, which are before the US Lehman Shock, one sub-period of 178 week, which is after the Lehman Shock, and one sub-period of 30 week, which is also after the Lehman Shock. That is, these four sub-periods are (1) from 24 November 2001 through 16 April 2005 (We denote this period as 'the first sub-period' hereafter.); (2) from 23 April, 2005 through 13 September 2008 (We denote this period as 'the middle sub-period' hereafter.); (3) from 20 September 2008 through 11 February 2012 (We denote this period as 'the latest sub-period' hereafter.); (4) from 20 September 2008 through 11 April 2009 (We denote this period as 'the LS sub-period' hereafter.). The last 30 week sub-period is the short-term period right after the Lehman Shock, which is largely influenced by the Lehman Shock.

Using four sub-periods described above and the data documented above, we implement the Welch's tests. This is for comparing the stock returns' correlation coefficients between the Japanese and the European stock markets in each sub-period. We exploit the historical correlation coefficients that are those of past 20 weeks. Our analysis includes the period of the Lehman Shock when correlations among international equity markets drastically change. Thus in order to avoid the difficulties in model estimations in such periods, we do not use any econometrical models in this paper. We note that the analysis used simple historical correlation coefficients in this paper derive highly robust evidence as we demonstrate in the next section. The null hypothesis in our Welch's tests is that, in two compared periods, the correlation coefficients' mean value of two markets' returns are equal. On the other hand, the alternative hypothesis in our Welch's tests is that, in two compared periods, the correlation coefficients' mean value of two markets' returns are not equal. Followings are more concrete descriptions of the alternative hypotheses for our five Welch's tests: (1) The correlation coefficients' average value in 'the first sub-period' is lower than the correlation coefficients' average value in 'the middle sub-period'; (2) The correlation coefficients' average value in 'the first sub-period' is lower than the correlation coefficients' average value in 'the latest sub-period'; (3) The correlation coefficients' average value in 'the first sub-period' is lower than the average value in 'the LS sub-period'; (4) The correlation coefficients' average value in 'the middle sub-period' is lower than the average value in 'the LS sub-period'; (5) The correlation coefficients' average value in 'the latest sub-period' is lower than the average value in 'the LS sub-period'. Moreover, the time-series developments of the correlation coefficients of returns between the Japanese and twelve European stock markets of Austria, Belgium, France, Germany, Greece, Ireland, Italy, Netherlands, Portugal, Spain, Switzerland, and England are displayed in Panels A to L in Figure 1.

\section{Empirical Results}

The empirical results are described in this section. (1) Firstly, as shown in Panel Bs of Tables 1 to 3 , the correlation coefficients between equity returns in the Japanese markets and the European markets increase in 'the middle sub-period' than in 'the first sub-period'. The two exceptions here are the results of Portugal and Spain. (2) Secondly, as indicated in Panels Cs of Tables 1 to 3, the correlations between the Japanese stock markets and all twelve European markets are higher in 'the latest sub-period' than in 'the first sub-period'. (3) Thirdly, as exhibited in Panel Ds of Tables 1 to 3, the correlations between the Japanese stock markets and all twelve European markets are higher in 'the LS sub-period' than in 'the first sub-period'. (4) Fourth, as indicated in Panels Es of Tables 1 to 3, the correlations between the Japanese stock markets and the European markets are higher in 'the LS sub-period' than in 'the middle sub-period'. The only one exception here is the result of Belgium. (5) Finally, as shown in Panels Fs of Tables 1 to 3, the correlations between the Japanese stock markets and the European markets are higher in 'the LS sub-period' than in 'the latest sub-period'. The two exceptions here are the results of Belgium and Ireland.

To sum up, our empirical examinations derived that the covariations of stock returns between the Japanese markets and the European markets recently gradually increased. Moreover, in the period right after the Lehman Shock, these connections of stock returns increased in particular. 


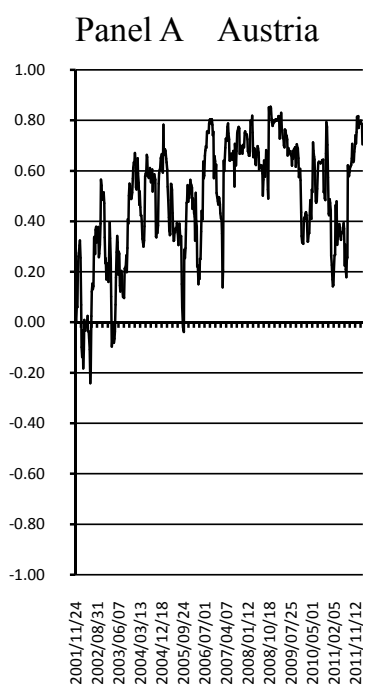

Panel E Greece

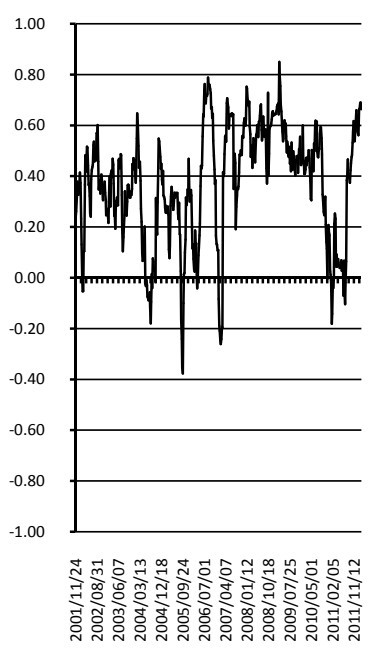

Panel I Portugal

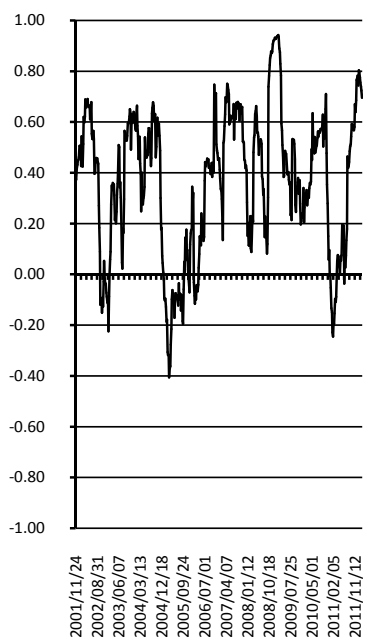

Panel B Belgium

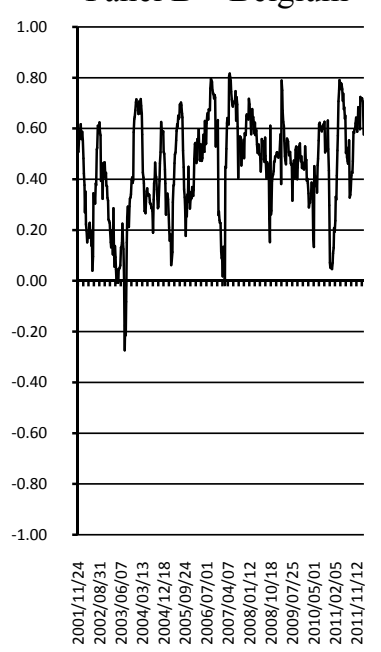

Panel F Ireland

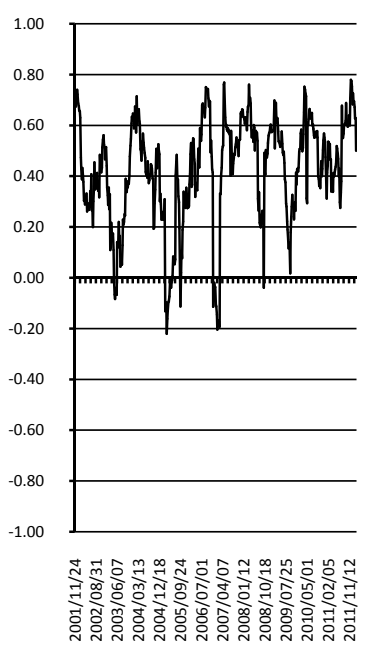

Panel J Spain

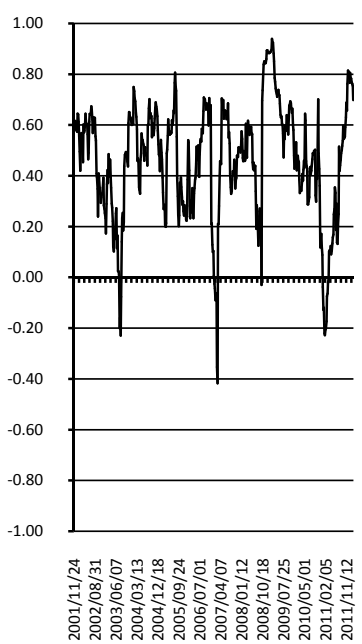

Panel C France

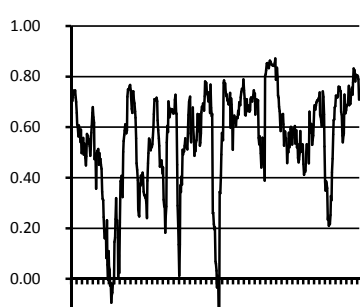

$-0.20$

$-0.40$

$-0.60$

$-1.00$

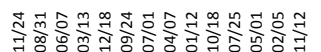

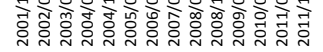

Panel G Italy

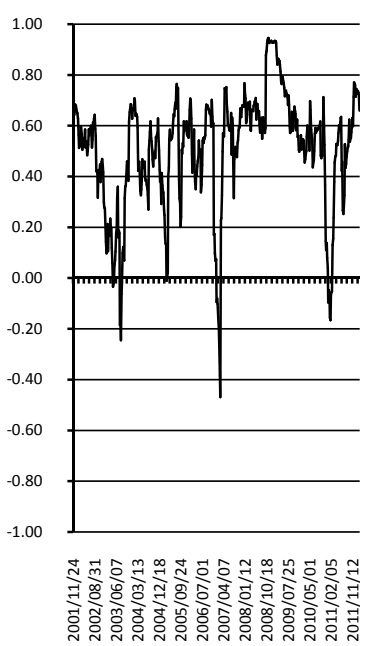

Panel K Switzerland

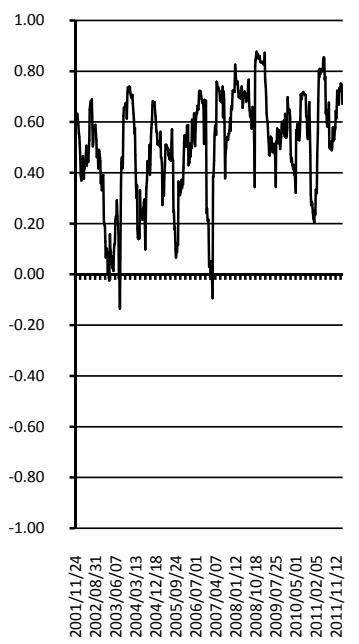

Panel D Germany

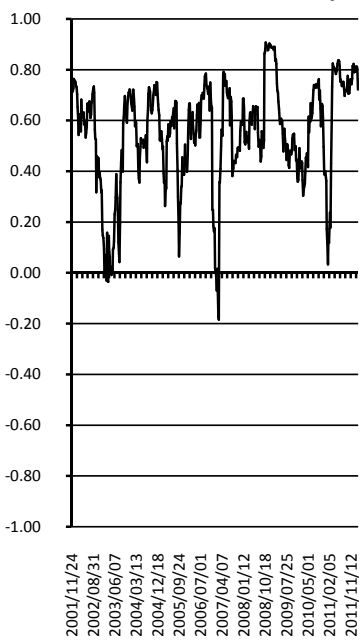

Panel H Netherlands

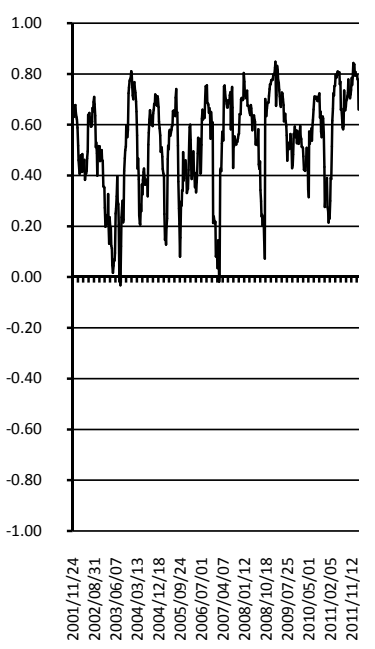

Panel L England

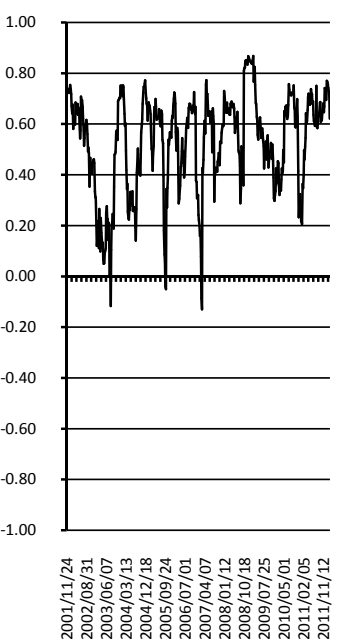

Figure 1. Correlations between the European and the Japanese Stock Markets 
Table 1. The Results of Welch's Tests: The Covariations with Austria, Belgium, France, and Germany

\begin{tabular}{llllll}
\hline \multicolumn{2}{l}{ Panel A } & Means and Standard Deviations of Correlation Coefficients of Returns for Four Periods & & \\
\hline Sample Periods & Statistic & Austria & Belgium & France & Germany \\
\hline $\begin{array}{l}\text { November 24, 2001 to } \\
\text { April 16, 2005 }\end{array}$ & SD & 0.3350 & 0.3369 & 0.4527 & 0.4949 \\
\hline April 23, 2005 to & Mean & 0.2384 & 0.2009 & 0.2118 & 0.2226 \\
September 13,2008 & SD & 0.5584 & 0.5298 & 0.5816 & 0.5302 \\
\hline September 20,2008 to & Mean & 0.1870 & 0.1674 & 0.1917 & 0.1887 \\
February 11,2012 & SD & 0.5806 & 0.4852 & 0.6281 & 0.6283 \\
September 20, 2008 to & Mean & 0.1843 & 0.1608 & 0.1517 & 0.1949 \\
April 11, 2009 & SD & 0.7738 & 0.4837 & 0.7869 & 0.8213 \\
\hline
\end{tabular}

Panel B Results for Welch's Tests: The Mean Value of the Correlation Coefficients of Returns for November 24, 2001 to April 16, $2005<$

The Mean Value of the Correlation Coefficients of Returns for April 23, 2005 to September 13, 2008

\begin{tabular}{|c|c|c|c|c|}
\hline$t$-value for Welch's tests & $9.8357^{* * *}$ & $9.8410^{* * *}$ & $6.0249^{* * *}$ & $1.6149^{*}$ \\
\hline$p$-value & 0.0000 & 0.0000 & 0.0000 & 0.0536 \\
\hline
\end{tabular}

Panel C Results for Welch's Tests: The Mean Value of the Correlation Coefficients of Returns for November 24, 2001 to April 16, $2005<$

The Mean Value of the Correlation Coefficients of Returns for September 20, 2008 to February 11, 2012

\begin{tabular}{lcccc}
\hline$t$-value for Welch's tests & $10.8720^{* * *}$ & $7.6880^{* * *}$ & $8.9847^{* * *}$ & $6.0154^{* * *}$ \\
$p$-value & 0.0000 & 0.0000 & 0.0000 & 0.0000 \\
\hline
\end{tabular}

Panel D Results for Welch's Tests: The Mean Value of the Correlation Coefficients of Returns for November 24, 2001 to April 16, $2005<$

The Mean Value of the Correlation Coefficients of Returns for September 20, 2008 to April 11, 2009

\begin{tabular}{|c|c|c|c|c|}
\hline$t$-value for Welch's tests & $18.6295^{* * *}$ & $4.9473^{* * *}$ & $12.3223^{* * *}$ & $11.6757^{* * *}$ \\
\hline$p$-value & 0.0000 & 0.0000 & 0.0000 & 0.0000 \\
\hline
\end{tabular}

Panel E Results for Welch's Tests: The Mean Value of the Correlation Coefficients of Returns for April 23, 2005 to September13, 2008 < The Mean Value of the Correlation Coefficients of Returns for September 20, 2008 to April 11, 2009

\begin{tabular}{lcccc}
\hline$t$-value for Welch's tests & $10.3648^{* * *}$ & -1.6199 & $7.8133^{* * *}$ & $10.9768^{* * *}$ \\
$p$-value & 0.0000 & - & 0.0000 & 0.0000 \\
\hline
\end{tabular}

Panel F Results for Welch's Tests: The Mean Value of the Correlation Coefficients of Returns for September 20, 2008 to February 11, 2012

$<$ The Mean Value of the Correlation Coefficients of Returns for September 20, 2008 to April 11, 2009

\begin{tabular}{lcccc}
\hline$t$-value for Welch's tests & $9.3603^{* * *}$ & -0.0540 & $6.4155^{* * *}$ & $7.2091^{* * *}$ \\
$p$-value & 0.0000 & - & 0.0000 & 0.0000 \\
\hline
\end{tabular}

Notes: In panel A, 'Mean' denotes the mean values of 20 week historical correlation coefficients between stock returns in the Japanese markets and in the European markets. Further, 'SD' means the standard deviations of 20 week historical correlation coefficients between stock returns in the Japanese markets and in the European markets. In panels B to $\mathrm{F},{ }^{* * *}$ denotes the statistical significance at the $1 \%$ level, ${ }^{* *}$ denotes the statistical significance at the $5 \%$ level, and ${ }^{*}$ denotes the statistical significance at the $10 \%$ level, respectively. 
Table 2. The Results of Welch's Tests: The Covariations with Greece, Ireland, Italy, and Netherlands

\begin{tabular}{|c|c|c|c|c|c|}
\hline Sample Periods & Statistic & Greece & Ireland & Italy & Netherlands \\
\hline November 24, 2001 to & Mean & 0.2991 & 0.3639 & 0.4070 & 0.4582 \\
\hline April 16, 2005 & SD & 0.1720 & 0.2027 & 0.2082 & 0.1996 \\
\hline April 23,2005 to & Mean & 0.4008 & 0.4094 & 0.5314 & 0.5222 \\
\hline September 13, 2008 & SD & 0.2676 & 0.2510 & 0.2131 & 0.1794 \\
\hline September 20, 2008 to & Mean & 0.4186 & 0.4917 & 0.5824 & 0.6181 \\
\hline February 11, 2012 & SD & 0.2212 & 0.1514 & 0.2357 & 0.1575 \\
\hline September 20,2008 to & Mean & 0.6233 & 0.5180 & 0.8762 & 0.6873 \\
\hline April 11, 2009 & SD & 0.1087 & 0.1522 & 0.1041 & 0.1937 \\
\hline
\end{tabular}

Panel B Results for Welch's Tests: The Mean Value of the Correlation Coefficients of Returns for November 24, 2001 to April 16, $2005<$

The Mean Value of the Correlation Coefficients of Returns for April 23, 2005 to September 13, 2008

\begin{tabular}{|c|c|c|c|c|}
\hline$t$-value for Welch's tests & $4.2673^{* * *}$ & $1.8839^{* *}$ & $5.5704^{* * *}$ & $3.1825^{* * * *}$ \\
\hline$p$-value & 0.0000 & 0.0302 & 0.0000 & 0.0008 \\
\hline
\end{tabular}

Panel C Results for Welch's Tests: The Mean Value of the Correlation Coefficients of Returns for November 24, 2001 to April 16, $2005<$

The Mean Value of the Correlation Coefficients of Returns for September 20, 2008 to February 11, 2012

\begin{tabular}{|c|c|c|c|c|}
\hline$t$-value for Welch's tests & $5.6903^{* * *}$ & $6.7433^{* * *}$ & $7.4417^{* * *}$ & $8.3898^{* * *}$ \\
\hline$p$-value & 0.0000 & 0.0000 & 0.0000 & 0.0000 \\
\hline
\end{tabular}

Panel D Results for Welch's Tests: The Mean Value of the Correlation Coefficients of Returns for November 24, 2001 to April 16, $2005<$

The Mean Value of the Correlation Coefficients of Returns for September 20, 2008 to April 11, 2009

\begin{tabular}{|c|c|c|c|c|}
\hline$t$-value for Welch's tests & $13.7044^{* * *}$ & $4.8687^{* * *}$ & $19.0733^{* * *}$ & $5.9675^{* * *}$ \\
\hline$p$-value & 0.0000 & 0.0000 & 0.0000 & 0.0000 \\
\hline
\end{tabular}

Panel E Results for Welch's Tests: The Mean Value of the Correlation Coefficients of Returns for April 23, 2005 to September13, 2008 < The Mean Value of the Correlation Coefficients of Returns for September 20, 2008 to April 11, 2009

\begin{tabular}{|c|c|c|c|c|}
\hline$t$-value for Welch's tests & $7.8873^{* * *}$ & $3.2369^{* * *}$ & $13.8831^{* * *}$ & $4.3645^{* * *}$ \\
\hline$p$-value & 0.0000 & 0.0010 & 0.0000 & 0.0000 \\
\hline
\end{tabular}

Panel F Results for Welch's Tests: The Mean Value of the Correlation Coefficients of Returns for September 20, 2008 to February 11, 2012

$<$ The Mean Value of the Correlation Coefficients of Returns for September 20, 2008 to April 11, 2009

\begin{tabular}{lcccc}
\hline$t$-value for Welch's tests & $7.9182^{* * *}$ & 0.8768 & $11.3200^{* * *}$ & $1.8571^{* *}$ \\
$p$-value & 0.0000 & 0.1930 & 0.0000 & 0.0357 \\
\hline
\end{tabular}

Notes: In panel A, 'Mean' denotes the mean values of 20 week historical correlation coefficients between stock returns in the Japanese markets and in the European markets. Further, 'SD' means the standard deviations of 20 week historical correlation coefficients between stock returns in the Japanese markets and in the European markets. In panels B to $\mathrm{F},{ }^{* * *}$ denotes the statistical significance at the $1 \%$ level, ${ }^{* *}$ denotes the statistical significance at the $5 \%$ level, and ${ }^{*}$ denotes the statistical significance at the $10 \%$ level, respectively. 
Table 3. The Results of Welch's Tests: The Covariations with Portugal, Spain, Switzerland, and England

\begin{tabular}{|c|c|c|c|c|c|}
\hline Sample Periods & Statistic & Portugal & Spain & Switzerland & England \\
\hline November 24,2001 to & Mean & 0.3519 & 0.4551 & 0.4148 & 0.4677 \\
\hline April 16, 2005 & SD & 0.2819 & 0.1890 & 0.2089 & 0.2167 \\
\hline April 23, 2005 to & Mean & 0.3144 & 0.4395 & 0.5340 & 0.5291 \\
\hline September 13, 2008 & SD & 0.2766 & 0.2030 & 0.2008 & 0.1715 \\
\hline September 20,2008 to & Mean & 0.4299 & 0.4900 & 0.6029 & 0.5976 \\
\hline February 11, 2012 & SD & 0.2924 & 0.2792 & 0.1605 & 0.1625 \\
\hline September 20,2008 to & Mean & 0.7797 & 0.7777 & 0.7675 & 0.7757 \\
\hline April 11, 2009 & SD & 0.2379 & 0.2375 & 0.1334 & 0.1341 \\
\hline \multicolumn{6}{|c|}{$\begin{array}{l}\text { Panel B Results for Welch's Tests: The Mean Value of the Correlation Coefficients of Returns for November 24, } 2001 \text { to April 16, } 2005< \\
\text { The Mean Value of the Correlation Coefficients of Returns for April 23, } 2005 \text { to September 13, 2008 }\end{array}$} \\
\hline$t$-value for Welch's tests & & -1.2670 & -0.7504 & $5.4873^{* * *}$ & $2.9652^{* * *}$ \\
\hline$p$-value & & - & - & 0.0000 & 0.0016 \\
\hline
\end{tabular}

Panel C Results for Welch's Tests: The Mean Value of the Correlation Coefficients of Returns for November 24, 2001 to April 16, $2005<$ The Mean Value of the Correlation Coefficients of Returns for September 20, 2008 to February 11, 2012

\begin{tabular}{|c|c|c|c|c|}
\hline$t$-value for Welch's tests & $2.5620^{* * *}$ & $1.3800^{*}$ & $9.5247^{* * *}$ & $6.3990^{* * *}$ \\
\hline$p$-value & 0.0054 & 0.0843 & 0.0000 & 0.0000 \\
\hline
\end{tabular}

Panel D Results for Welch's Tests: The Mean Value of the Correlation Coefficients of Returns for November 24, 2001 to April 16, $2005<$ The Mean Value of the Correlation Coefficients of Returns for September 20, 2008 to April 11, 2009

\begin{tabular}{|c|c|c|c|c|}
\hline$t$-value for Welch's tests & $8.8555^{* * *}$ & $7.0724^{* * *}$ & $12.1786^{* * *}$ & $10.4840^{* * *}$ \\
\hline$p$-value & 0.0000 & 0.0000 & 0.0000 & 0.0000 \\
\hline
\end{tabular}

Panel E Results for Welch's Tests: The Mean Value of the Correlation Coefficients of Returns for April 23, 2005 to September13, 2008 < The Mean Value of the Correlation Coefficients of Returns for September 20, 2008 to April 11, 2009

\begin{tabular}{|c|c|c|c|c|}
\hline$t$-value for Welch's tests & $9.6669^{* * *}$ & $7.3602^{* * *}$ & $8.1537^{* * *}$ & $8.9186^{* * *}$ \\
\hline$p$-value & 0.0000 & 0.0000 & 0.0000 & 0.0000 \\
\hline
\end{tabular}

Panel F Results for Welch's Tests: The Mean Value of the Correlation Coefficients of Returns for September 20, 2008 to February 11, 2012 $<$ The Mean Value of the Correlation Coefficients of Returns for September 20, 2008 to April 11, 2009

\begin{tabular}{|c|c|c|c|c|}
\hline$t$-value for Welch's tests & $7.1889^{* * *}$ & $5.9766^{* * *}$ & $6.0589^{* * *}$ & $6.5137^{* * *}$ \\
\hline$p$-value & 0.0000 & 0.0000 & 0.0000 & 0.0000 \\
\hline
\end{tabular}

Notes: In panel A, 'Mean' denotes the mean values of 20 week historical correlation coefficients between stock returns in the Japanese markets and in the European markets. Further, 'SD' means the standard deviations of 20 week historical correlation coefficients between stock returns in the Japanese markets and in the European markets. In panels B to F, ${ }^{* * *}$ denotes the statistical significance at the $1 \%$ level, ${ }^{* *}$ denotes the statistical significance at the $5 \%$ level, and " denotes the statistical significance at the $10 \%$ level, respectively.

\section{Interpretation and Implications}

The empirical results shown above indicate that the international diversifications in stock portfolios become less important in equity portfolio managements. However, the value of foreign equities changes according to the changes of foreign exchange rates. Thus, the relationships between foreign exchange rate risk and expected stock returns will be more and more important for the future equity portfolio management. This is the first interpretation and implication from our study. We consider that this kind of research may be our future another work.

In addition, increasing market integrations of the international stock markets indicated by our empirical examinations suggest that other non-traditional asset classes such as commodities or real estate are also increasingly important for the future management of portfolios, where investment assets are not limited to only equities. This is the second implication derived from our study.

Further, the particular increases of the covariations between the international equity markets in the highly stressed markets suggest that the importance of forecasting market crashes or financial crises by effective indicators. For example, watching investor sentiment might be effective for forecasting these market frictions. 


\section{Conclusions}

In this paper, we performed the empirical tests as to the time-series stock return connections between the Japanese markets and twelve European markets of Austria, Belgium, France, Germany, Greece, Ireland, Italy, Netherlands, Portugal, Spain, Switzerland, and England. In our examinations, the focus was particularly on the differences of the stock return correlation coefficients in the periods which are before and after the US Lehman Shock. Our empirical examinations conducted in this paper offered the following novel contributions.

1. Firstly, it was statistically revealed that recently, the stock return correlations between the Japanese and the European equity markets presented gradual increases.

2. Secondly, it was empirically derived that the time-series linkage between stock returns of the Japanese markets and the European equity markets generally increased in the sub-period, which was right after the US Lehman Shock.

As we summarized above, the derived findings by our formal statistical tests conducted in this research will contribute to the body of academic research in economics, business, and finance. It is considered that the future related analyses by exploiting our findings and other related data may be also valuable, and these researches are our future works.

\section{Acknowledgements}

The author acknowledges the Japan Society for the Promotion of Science for their generous financial assistance for this research. In addition, I also thank anonymous referees and the Editor for their kind comments to this paper. Furthermore, I greatly appreciate the repeated kind invitation from the Editors to write to this journal.

\section{References}

Bekaert, G., \& Harvey, C. (1995). Time-varying world market integration. Journal of Finance, 50, 403-444. http://dx.doi.org/10.2307/2329414

Bekaert, G., Campbell, R. H., \& Robin, L. L. (2002). Dating the integration of world equity markets. Journal of Financial Economics, 65, 203-247. http://dx.doi.org/10.1016/S0304-405X(02)00139-3

Bekaert, G., Harvey, C., \& Ng, A. (2005). Market integration and contagion. Journal of Business, 78, 39-69.

Billio, M., Getmansky, M., Lo, A. W., \& Pelizzon, L. (2012). Econometric measures of connectedness and systemic risk in the finance and insurance sectors. Journal of Financial Economics, 104(3), 535-559. http://dx.doi.org/10.1016/j.jfineco.2011.12.010

Boyson, N. M., Stahel, C. W., \& Stulz, R. M. (2010). Hedge fund contagion and liquidity shocks. Journal of Finance, 5, 1789-1816. http://dx.doi.org/10.1111/j.1540-6261.2010.01594.x

Forbes, K. J., \& Rigobon, R. (2002). No contagion, only interdependence: measuring stock market comovements. Journal of Finance, 57, 2223-2261. http://dx.doi.org/10.1111/0022-1082.00494

Heston, S., \& Rouwenhorst, K. (1994). Does industrial structure explain the benefits of international $\begin{array}{lllll}\text { diversification?. Journal of } & \text { Financial }\end{array}$ http://dx.doi.org/10.1016/0304-405X(94)90028-0

Longin, F., \& Solnik, B. (2001). Extreme correlation of international equity markets. Journal of Finance, 56, 649-676. http://dx.doi.org/10.1111/0022-1082.00340

Pukthuanthong, K., \& Roll, R. (2009). Global market integration: An alternative measure and its application. Journal of Financial Economics, 94, 214-232. http://dx.doi.org/10.1016/j.jfineco.2008.12.004

Rouwenhorst, G. K. (1999). Local return factors and turnover in emerging stock markets. Journal of Finance, 54, 1439-1464. http://dx.doi.org/10.1111/0022-1082.00151 